\title{
Utilização da hemogasometria em ovinos atendidos no Hospital Veterinário da UEL
}

Bruno Ambrozini", Lucas Monteiro do Carmo, Lucas Vinícius Oliveira Ferreira, Karina Keller Marques da Costa Flaiban, Júlio Augusto Naylor Lisbôa, Priscilla Fajardo Valente Pereira

Universidade Estadual de Londrina (UEL), Londrina, PR, Brasil

*Autor correspondente

e-mail: bruno_ambrozini@hotmail.com

\section{Resumo}

Com o crescimento da ovinocultura e aumento no número e na intensidade do manejo de ovinos confinados, ocorreu também um crescimento na ocorrência de enfermidades. 0 exame gasométrico é uma ferramenta que está ganhando cada vez mais espaço, principalmente dentro de hospitais veterinários, devido ao auxílio no diagnóstico e tratamentos mais eficientes. 0 objetivo deste trabalho foi estudar os principais desequilíbrios ácido-base de ovinos da região norte do Paraná, atendidos no Ambulatório de Grandes Animais do Hospital Veterinário da Universidade Estadual de Londrina (HV-UEL). Para isso, foram revisadas fichas clínicas de ovinos atendidos no período de janeiro de 2010 a dezembro de 2016, em que foi necessária a realização de exame hemogasométrico. Os dados coletados foram diagnóstico, achados da gasometria e evolução dos casos (alta, óbito, eutanásia). Um estudo descritivo foi realizado, observando a distribuição das frequências (\%). 0 exame gasométrico foi realizado em 25 ovinos e duas enfermidades foram mais frequentes: acidose ruminal lática aguda (ALRA) em seis casos (24\%) e Hemoncose em cinco casos (20\%). Dos ovinos acometidos por ALRA, todos (100\%) apresentaram acidose metabólica, porém apenas 66,7\% tinham acidemia, enquanto 33,3\% apresentaram pH sanguíneo dentro dos valores de referência da espécie. Em relação aos eletrólitos, a maioria dos animais apresentou normonatremia (66,6\%), hipocalemia (100\%), hipercloremia (83,3\%) e hipocalcemia (66,6\%). A taxa de mortalidade dos animais com ALRA foi de 50\%. Nos animais diagnosticados com Hemoncose, a frequência de acidose metabólica e alcalose metabólica foi de $20 \%$ em ambas as condições e $60 \%$ dos animais não apresentaram alterações no equilíbrio ácidobase. Nenhum animal apresentou alteração na concentração sérica de sódio e $60 \%$ dos animais apresentou normocalemia. Porém, em $80 \%$ dos animais com hemoncose, hipercloremia e hipocalcemia estavam presentes. A maioria dos animais diagnosticados com hemoncose foram a óbito (60\%). Os ovinos restantes ( $n=14$, ou seja, $56 \%$ ) foram diagnosticados com diferentes enfermidades e $57,1 \%$ deles apresentavam 
acidose metabólica, 28,6\% não apresentavam desequilíbrio ácido-base e 14,3\% apresentavam alcalose metabólica. Em relação aos eletrólitos, observou-se 50\% de casos sem alteração na concentração sérica de sódio, 78,6\% de hipocalemia, 64,3\% de hipercloremia e 85,7\% de hipocalcemia. Somente 28,6\% desses animais tiveram alta clínica. Pode-se concluir que nos ovinos atendidos no HV-UEL, o desequilíbrio ácidobase mais frequente foi a acidose metabólica. A hipocalcemia foi o desequilíbrio eletrolítico mais encontrado, independente do diagnóstico. São necessários outros estudos para o estabelecimento de uma correlação estatística entre as variáveis, mas na análise prévia deste trabalho, percebe-se a grande importância do exame gasométrico para o melhor tratamento de tais enfermidades. 